\title{
Neurological Manifestations of Novel Coronavirus Disease in a 2-Month-Old Infant: A Case Report
}

\author{
Mojtaba Kamali Aghdam ${ }^{1}$ Hassan Bakhtiari $^{1}$ Diana Noemi Diaz $^{1}$ Kambiz Eftekhari $^{2}$ Ka $^{\circ}$ \\ 1 Pediatrics Department, Mousavi Hospital, Zanjan University of \\ Medical Sciences, Zanjan, Iran \\ 2 Department of Pediatrics, Pediatric Gastroenterology and \\ Hepatology Research Center, Tehran University of Medical Sciences, \\ Bahrami Children's Hospital, Tehran, Iran \\ J Pediatr Neurol 2021;19:210-212. \\ Address for correspondence Kambiz Eftekhari, MD, Department of \\ Pediatrics, Bahrami Children's Hospital, Kiaee Street, Tehran \\ 1641744991, Iran (e-mail: dr_k_eftekhary@yahoo.com).
}

\begin{abstract}
Keywords

- infants

- neurological symptoms

- novel coronavirus

The main manifestations of novel coronavirus usually include fever and cough. Neurological manifestations have not been properly identified in children. A 65-dayold infant was hospitalized due to poor feeding, weakness, lethargy, and occasional cough. She suffered several seizures during her hospitalization. The brain computed tomography scan depicted a minor hemorrhage. Due to the exacerbation of her condition during hospital stay and the presence of respiratory symptoms in her parents, coronavirus disease was suspected. Reverse transcription-polymerase chain reaction (PCR) of coronavirus was positive for both: child and parents. In children with neurological manifestations such as lethargy, recurrent seizures, cerebral hemorrhage, and clinical evidence of respiratory symptoms in his/her relatives, PCR testing for coronavirus is recommended.
\end{abstract}

\section{Introduction}

In December 2019, coronavirus 2019 (severe acute respiratory syndrome coronavirus 2) appeared in China. It rapidly expanded in China and worldwide. ${ }^{1}$ It is now referred to as coronavirus disease 2019 (COVID-19). ${ }^{1}$ The disease is usually milder in children than in adults, and it may be associated with nonspecific symptoms. ${ }^{2}$ In a review article (January 1 to March 18 , 2020), 1 to $5 \%$ of all COVID-19 cases were found in children. ${ }^{3}$ One study suggested that approximately $16 \%$ of children with COVID-19 were asymptomatic, $19 \%$ had upper respiratory infection, and $65 \%$ pneumonia. ${ }^{4}$ The most common symptoms of the disease include cough (48.5\%), pharyngeal erythema (42.2\%), and fever (41.5\%). ${ }^{4}$ Diarrhea, fatigue, rhinorrhea, and vomiting are less common. ${ }^{4}$ Wang et al reported that $36.4 \%$ of adults with COVID-19 had neurological symptoms, including headache, dizziness, weakness, cerebral hemorrhage, and infarction. ${ }^{5}$ This study indicated that despite the high

received

June 23, 2020

accepted after revision

July 8, 2020

published online

September 2, 2020

incidence of cerebral hemorrhage in patients with COVID-19, the physiological relationship between COVID-19 and cerebral hemorrhage is still unclear. ${ }^{5}$ Filatov et al discussed a 74-yearold patient with encephalopathy and decrease of consciousness in the field of COVID-19. ${ }^{6}$ So far, there are no reliable reports of neurological manifestations in children. Our purpose is to report the presence of neurological manifestations in infants with COVID-19. Health care providers should be aware that children with COVID-19 may also have a clinical picture of neurological involvement.

\section{Case Presentation}

A 65-day-old female infant was brought to Mousavi Hospital in Zanjan (Iran) due to poor feeding, weakness, lethargy, and occasional cough. She is the first child of nonconsanguineous parents born by cesarean section with a birthweight of $3,400 \mathrm{~g}$. The current weight was $6,000 \mathrm{~g}$, indication of a

(c) 2020. Thieme. All rights reserved. Georg Thieme Verlag KG,

Rüdigerstraße 14,

70469 Stuttgart, Germany
DOI https://doi.org/ 10.1055/s-0040-1716393. ISSN 1304-2580. 
good growth. She was being breastfed. The parents themselves complained of fever and cough for several days, and the mother still coughed. The infant was initially restless and agitated without fever, but with tachypnea (respiratory rate 56 per minute) and tachycardia (pulse rate 190 per minute). Her past medical history was significant for very mild- and low-energy trauma, but there were no bruises (ecchymosis) or scratches suggesting trauma in any part of the body. This trauma could not justify the clinical manifestations due to its very mild nature. She was immediately transferred to the pediatric intensive care unit. The first step of the management was to evaluate for infections, which required the culture of the blood, urine, and cerebrospinal fluid (CSF) samples. Fluid therapy was started, and then the necessary paraclinical tests especially blood and urine cultures were sent. After admission, short-generalized seizures occurred, and were controlled with diazepam $(0.2 \mathrm{mg} / \mathrm{kg}$ over 2 minutes IV administration) and phenytoin ( $20 \mathrm{mg} / \mathrm{kg}$ loading dose). Then brain computed tomography (CT) scans were performed, which showed a hyperdense center with a diameter of $5 \mathrm{~mm}$ in the cortical part of the left temporal lobe, indicative of hemorrhage (-Fig 1). It was not possible to perform LP due to this hemorrhage, and the child was continued on supportive care and maintenance therapy. As she presented with sepsis-like symptoms and leukopenia, treatment was started with broad-spectrum antibiotics: vancomycin $(15 \mathrm{mg} / \mathrm{kg} / \mathrm{q} 6 \mathrm{~h}$ made by Exir Pharmaceutical Co., Iran) and meropenem $40 \mathrm{mg} / \mathrm{kg} / \mathrm{q} 8 \mathrm{~h}$ made by Dana Pharmaceutical Co., Iran). On the other hand, as there was evidence of respiratory symptoms in her parents and coincidence with coronavirus epidemic, COVID-19 was suspected. reverse-transcription polymerase chain reaction (RT-PCR) assay was performed in child and her mother by throat sampling. The infant was isolated. Before the PCR results were available, generalized-seizures occurred several times,

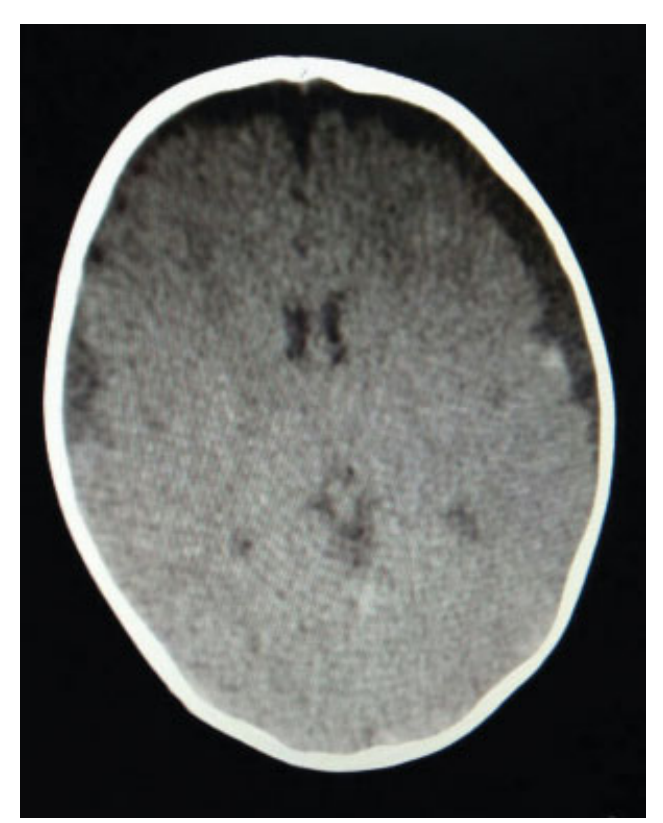

Fig. 1 The brain computed tomography scan of a 2-month-old infant with coronavirus disease 2019. which were controlled with diazepam and phenobarbital (10 $\mathrm{mg} / \mathrm{kg}$ loading dose) in addition to phenytoin. A new brain CT scan was conducted, but no changes were observed in the brain lesion. Electroencephalogram (EEG) showed low voltage slow- wave activity. This finding suggested the possibility of a diffuse cerebral phenomenon such as encephalopathy or viral encephalitis. ${ }^{7}$ The chest X-ray was normal. Blood and urine cultures were negative. The results of the laboratory tests were as noted below:

White blood cell count $=1.4 \times 10^{3} / \mu \mathrm{L}$ (L: $68 \%, \mathrm{~N}: 30 \%$ ), (normal range: $4-10 \times 10^{3} / \mu \mathrm{L}$ ), hemoglobin $=10.1 \mathrm{~g} / \mathrm{dL}$, platelet count $=183 \times 10^{3} / \mu \mathrm{L}$ (normal range: $150-450 \times 10^{6} / \mu \mathrm{L}$ ), blood sugar $=110 \mathrm{mg} / \mathrm{dL}$ (normal range: $50-115 \mathrm{mg} / \mathrm{dL}$ ), calcium $=9.4 \mathrm{mg} / \mathrm{dL}$ (normal range: $8-13 \mathrm{mg} / \mathrm{dL}$ ), sodium $=$ $139 \mathrm{mEq} / \mathrm{L}$ (normal range: $136-146 \mathrm{mEq} / \mathrm{L}$ ), potassium $=$ $4.5 \mathrm{mEq} / \mathrm{L}$ (normal range: $3.5-5.1 \mathrm{mEq} / \mathrm{L}$ ), c-reactive protein = $3 \mathrm{mg} / \mathrm{dL}$ (normal range: $<5$ Negative), prothrombin time $=13$ seconds (normal range: 11-14 seconds), international normalized ratio $=1$, prothrombin time $=38.7$ seconds (normal range: $24-40$ seconds), lactate dehydrogenase $=761 \mathrm{U} / \mathrm{L}$ (normal range: 230-460 U/L)

The RT-PCR of coronavirus was positive in both infant and mother. Based on the results, the diagnosis of COVID-19 was confirmed. Hydroxychloroquine $(1.5 \mathrm{mg} / \mathrm{kg} / \mathrm{q} 12 \mathrm{~h}$ made by Tehran Daru Company., Iran) was added to the treatment. Weakness and lethargy gradually disappeared within a week, and the child regained her appetite. The clinical symptoms completely improved with supportive care, antibiotics, hydroxychloroquine, and anticonvulsants. The seizures did not recur. Finally, after 14 days, she was discharged from hospital. Home treatment with oral phenytoin ( $5 \mathrm{mg} / \mathrm{kg} /$ day) and phenobarbital $(5 \mathrm{mg} / \mathrm{kg} /$ day) was prescribed. At present, she is being followed and her condition is completely satisfactory.

\section{Discussion}

The clinical symptoms of COVID-19 are relatively milder in children than in adults and usually include fever and respiratory distress. Of course, other manifestations such as sore throat, upper respiratory tract infections, and gastrointestinal symptoms may also be seen. ${ }^{2}$ Cerebral involvement and neurological manifestations have not been reported in children, ${ }^{8}$ but in adults especially in the elderly, encephalopathy and other neurological problems have been reported. ${ }^{5,6}$ In some adult studies, central nervous system (CNS) symptoms such as dizziness, weakness, lethargy, and unstable gait were reported. ${ }^{5}$ In some cases, even cerebral hemorrhage was evident. ${ }^{5}$ Although research in this area is very limited, there is a theory that postulates that a cerebral hemorrhage could follow a COVID-19 infection. ${ }^{5}$ In searching the literature, we did not find any COVID-19-related neurological manifestations in children. ${ }^{9}$

In our case, in addition to the symptoms of COVID-19, there was the history of mild trauma. It should be noted that her main symptoms were present before the trauma. This trauma happened during her transfer to the hospital, and it had a very mild and negligible nature. So, given the mild nature of the trauma and EEG findings, it could be possible that the bleeding and 
seizures could be related to the to the COVID disease. In addition, coagulopathy disorders, as one of the causes of the cerebral hemorrhage, were ruled out due to the normal coagulation tests. Based on these findings, it can be reasonably concluded that the cause of bleeding was the coronavirus infection.

Although the definitive diagnosis of viral encephalitis depends on the identification of the virus from the CSF, the clinical evaluation of neurological manifestations is also important for diagnosis. Based on neurological symptoms, including poor feeding, weakness, lethargy, recurrent seizures, and EEG findings, we suggested the possibility of encephalitis.

It is recommended that, in children presenting with neurological and respiratory symptoms, especially if there is clinical evidence of respiratory symptoms in their relatives, leukopenia and increased LDH in her blood tests, COVID-19 should be considered. It should be noted that in most cases published in the literature, such as our patient, the infected child with coronavirus has a history of close contact with this infection in his/her relatives. ${ }^{8-11}$ As a result, immediate isolation is important to prevent the spread of the disease. In cases where COVID-19 is confirmed, more accurate and specific treatment can be provided.

Conflict of Interest

None declared.

\section{References}

1 McIntosh K, Hirsch MS, Bloom A. Coronavirus disease 2019 (COVID19): Epidemiology, virology, and prevention. Avaialable at: https:// www.uptodate.com/contents/coronavirus-disease-2019-covid-19 -epidemiology-virology-and-prevention. Accessed July 20, 2020

2 Lu Q Shi Y. Coronavirus disease (COVID-19) and neonate: what neonatologist need to know. J Med Virol 2020;92(06):564-567

3 Ludvigsson JF. Systematic review of COVID-19 in children shows milder cases and a better prognosis than adults. Acta Paediatr 2020;109(06):1088-1095

4 Lu X, Zhang L, Du H, et al; Chinese Pediatric Novel Coronavirus Study Team. SARS-CoV-2 infection in children. N Engl J Med 2020; 382(17):1663-1665

5 Wang H-Y, Li X-L, Yan Z-R, Sun X-P, Han J, Zhang B-W. Potential neurological symptoms of COVID-19. Ther Adv Neurol Disorder 2020;13. Doi: 1756286420917830

6 Filatov A, Sharma P, Hindi F, Espinosa PS. Neurological complications of coronavirus disease (COVID-19): encephalopathy. Cureus 2020;12(03):e7352

7 Andrew B. Janowski, David A. Hunstad. Viral Meningoencephalitis. In: Kliengman RM, Stanton BF, St Geme JW, Schor NF, eds. . Nelson Text book of pediatrics. 20th ed. Philadelphia: Saunders Elsevier; 2019:3232-3234

8 Panda PK, Sharawat IK. COVID-19 (SARS-CoV-2 infection) and children: pediatric neurologist's perspective. Indian J Pediatr 2020;87(07):556-557

9 Chacón-Aguilar R, Osorio-Cámara JM, Sanjurjo-Jimenez I, GonzálezGonzález C, López-Carnero J, Pérez-Moneo-Agapito B. COVID-19: fever syndrome and neurological symptoms in a neonate. An Pediatr (Engl Ed) 2020;92(06):373-374

10 Zimmermann P, Curtis N. Coronavirus infections in children including COVID-19: an overview of the epidemiology, clinical features, diagnosis, treatment and prevention options in children. Pediatr Infect Dis J 2020;39(05):355-368

11 Kamali Aghdam M, Jafari N, Eftekhari K. Novel coronavirus in a 15day-old neonate with clinical signs of sepsis, a case report. Infect Dis (Lond) 2020;52(06):427-429 